\title{
Turfing
}

\section{Patients in the Balance}

\author{
David T. Stern, MD, PhD, Catherine V. Caldicott, MD
}

OBJECTIVE: To examine the language of "turfing," a ubiquitous term applied to some transfers of patients between physicians, in order to reveal aspects of the ideology of internal medicine residency.

SETTING: Academic internal medicine training program.

MEASUREMENTS: Using direct observation and a focus group, we collected audiotapes of medical residents' discussions of turfing. These data were analyzed using interpretive and conversation analytic methods. The focus group was used both to validate and to further elaborate a schematic conceptual framework for turfing.

MAIN RESULTS: The decision to call a patient "turfed" depends on the balance of the values of effectiveness of therapy, continuity of care, and power. For example, if the receiving physician cannot provide a more effective therapy than can the transferring physician, medical residents consider the transfer inappropriate, and call the patient a turf. With appropriate transfers, these residents see their service as honorable, but with turfs, residents talk about the irresponsibility of transferring physicians, burdens of service, abuse, and powerlessness.

CONCLUSIONS: Internal medicine residents can feel angry and frustrated about receiving patients perceived to be rejected by other doctors, and powerless to prevent the transfer of those patients for whom they may have no effective treatment or continuous relationship. This study has implications for further exploration of how the relationships between physicians may uphold or conflict with the underlying moral tenets of the medical profession.

KEY WORDS: residency; patient transfers; turfing; professional relationships; professional values.

J GEN INTERN MED 1999;14:243-248.

$\mathbf{T}$ urfing, a colloquialism in academic medicine, applies to some transfers of patients between physicians. In one study of socialization into the medical profession, turfing was one of the most frequently identified areas of professional conflict. ${ }^{1}$ By probing the language that medical residents use when discussing turfs, we hoped to identify the underlying meaning of turfing, to expose the

Received from the Division of General Internal Medicine, Department of Internal Medicine, Ann Arbor Veterans Administration Hospital, and The Robert Wood Johnson Clinical Scholars Program, University of Michigan, Ann Arbor, Mich (DTS, CVC).

Dr. Caldicott is now with the Division of General Medicine, SUNY Health Science Center, Syracuse, NY.

Address correspondence and reprint requests to Dr. Stern: Ambulatory Care (11A), 2215 Fuller Rd., Ann Arbor, MI 48105. feelings and behaviors it evokes, and to illuminate the ideology of internal medicine residency surrounding patient transfers and interprofessional relationships.

Turf was first used to mean "a sod of grass, with the roots and earth adhering," such as the turf on which cattle graze, or the turf on which a football game is played. In the 1430s, turf also began to be used as a verb meaning "to cover with turf." By the late 19th century, the verb form also meant to throw or kick forcibly out-"The colonel will turf you out of that in double quick time," ${ }^{2}$-implying that a person was forcibly thrown out onto the turf. Nowadays, some patients transferred from one doctor's care to another are referred to as having been "turfed." The individual doctor or service becomes a territory, and the patient is moved (turfed) from one to another.

Because medical slang provides a window to the focal concerns, preoccupations, values, and tensions of the medical residents' worldview, ${ }^{3}$ we wondered why medical residents have slang terms for some transfers but not for others. We wondered how medical residents decide which transfers should be labeled as turfs, and why turfing becomes such an emotionally charged issue. These questions bear directly on the development of professional values in medical trainees.

\section{METHODS}

The data for this study derive from two sources: a set of 15 audiotaped excerpts from a previous study on teaching values in internal medicine ${ }^{1}$ and the audiotape of a resident focus group convened to discuss turfing. All study subjects agreed to participate and to be taperecorded.

As described elsewhere, ${ }^{4}$ the 15 excerpts were collected in the course of a study of internal medicine teams in a tertiary care university hospital and its associated Veterans Administration hospital. Accompanying the teams on their daily routines, the researchers audiotaped and recorded observations in field notes during 194 hours of inpatient service. The tapes and notes were transcribed, and content analysis was used to identify excerpts containing the teaching of values. ${ }^{5}$ The identification of such values statements from the stream of narrative was a highly reliable process (interrater agreement $>95 \%$ ). The values taught in each excerpt were identified by the researchers, then validated by means of triangulation of participants, researchers, and informed insiders. Discussions of turfing were the most frequent topics found in these transcripts (15 of 98 excerpts in which values were found to be in conflict). ${ }^{4}$ 
To provide additional depth to our understanding of the issues involved in turfing, we convened a focus group of six second- and third-year internal medicine residents from the same training program in which the initial observations were made. The focus group participants were not aware of the findings of the aforementioned teaching of values study. Run by a trained facilitator (not one of the investigators), the research investigators were not present during the group's discussion. The audiotape of the focus group, its transcription, and the field notes made by the group's facilitator constitute the second source of data.

All transcribed data (from the observational study and focus group) were analyzed using qualitative content analysis techniques. Three of the excerpts from the observational study that were felt to provide particularly rich examples of turfing were chosen for a more detailed linguistic analysis. Each was transcribed using accepted linguistic transcription conventions. ${ }^{6}$ These transcripts were examined according to the principles of conversation analysis, an inductive procedure that shows how aspects of language delivery suggest meaning and point of view. ${ }^{7}$ For example, a conversation analyst observes, describes, and then explicates the structure and patterns of a dialogue that allow conversationalists to achieve a mood, intent, and social order. Examples of structure and patterns include turn-taking behavior, simultaneous speech, and vocal inflection (intensity, pitch, fluency). ${ }^{8}$ (Transcripts of conversations capture only a portion of their linguistic character. As a supplementary source of meaning and point of view, audio reenactments of actual turfing excerpts can be found at http://www.med.umich. edu/lrc/stern/turfing. In all transcripts and audio segments, participants' names have been changed to ensure confidentiality.)

Our analyses move from data to interpretation, and back again to the data for confirmation or refutation of the interpretation. A standard way to interpret qualitative data, ${ }^{9}$ this iterative process provides a means to understand rather than establish cause or correlation. Validation of the themes occurs through this iterative process. In addition,the focus group confirmed the basic elements of our conceptual framework and enriched our insight into the meaning of turfing within an academic internal medicine training program. During the data analysis phase, our methods were formally presented and critiqued in a work-in-progress seminar before 11 physicians and three professors from linguistics, sociology, and health services research.

\section{RESULTS}

\section{Thematic Analysis of Turfing}

Continuity. The residents place great importance on continuity in the doctor-patient relationship. They find discontinuity of care to be acceptable only if they perceive a medical necessity for the transfer, such as moving a patient to a facility where there are experts or technologies unavailable at the patient's home institution. Transfers are called turfs when they are perceived as having been made at the convenience of the transferring doctor-such as when he or she loses the desire to take care of the patient, or when the diagnosis-related group reimbursement "runs out."

[N]aturally I would find it, uh, disturbing . . . when maybe it's more of a self-serving move on the part of the physician making the transfer.

More than just disruptive and inconvenient, discontinuity of care is also felt to be medically unwise. The frustrations of turfing threaten to carry over into the relationship with and care of the patient.

And I think that's probably bad for patient care too because . . we have to relearn everything and . . . we may miss out on little things just because, I mean, we're not that motivated cuz we already have these, you know, negative feelings.

Turfing physicians were felt to abdicate their responsibility to care for the patient.

I think ultimately there's a, there's a sense of, I don't know, a right and wrong, at least within the department of medicine, that once a patient is on your service, they're going to stay on your service until you're done taking care of the issues. I don't think you find any of the medical services taking patients and moving them to other services. I think many of us think it's a shame that that's not the case on some of the other services. That there's not that same philosophy or that same maybe morality even.

Effectiveness. Residents believe that when the receiving physician can provide technical services or intellectual expertise unavailable either at an outside hospital or on another service within their own institution, the transfer is appropriate. However, residents label the transfer a turf if the receiving physician can provide no more effective treatment than the transferring physician. The following sequence of quotations illustrates how medical residents distinguish between effective and ineffective care:

People usually move patients either because of, uh, an ability issue or capability issue. "I feel incapable. I'm throwing my hands up in the air. I don't know what to do here. Um, they have diabetes. They have coronary disease. I'm a surgeon. I haven't thought about these things since medical school." For us, it's simple, we deal with it every day, and we look at that and say, "I mean, why can't you deal with this, you're a doctor." But for them they're in the OR all day. They're not thinking about those things. They're thinking about operative issues, and so it's a, "I don't feel capable of this. Help!" And you know and they look to us. But that's just one-half of it. And I don't think that's inappropriate . . . as long as there's some room there for you to do something.

What makes it inappropriate is when someone moves a patient from one place to another and there's no benefit to the patient by doing so. 
I think we all went into the profession to be utilized-not to be used. And I think that you feel as if perhaps you're just being used when you feel like you can't do anything extra and it's just the fact that you're another body and it's, it's work or burden off someone else's shoulders.

Power. Residents express frustration and anger about their lack of power on the receiving end of a turf. This powerlessness has two sources. First, it is a function of residency, where the inverse relation between authority and workload is a well-known attribute of the medical education system. ${ }^{10}$

\begin{abstract}
The people making the decisions aren't the ones who are really integrally involved in, in the day-to-day care . . . [T]he care ... falls within, uh, you know, our responsibility. And so, um, if we're unhappy with the situation, um, you would think that we might have a voice to do something about it, or might have some influence, but it just, it doesn't work that way.
\end{abstract}

Second, it is a function of perceived interdepartmental cultural and philosophical differences, with medicine/ surgery undisputedly the most salient exemplar in our data. In contrast to the resident quoted under the Effectiveness section above, with whom the surgeon has communicated his or her point of view, most of the medical residents on our tapes feel that the surgeons foist their work and responsibilities upon them, without displaying any other collegial behavior.

\section{[I]t's almost like it's their call. Do they want to take the patient or not? And if they don't, and that person needs to be in the hospital, then it will be a medicine patient. \\ Because I guess the way medicine is, is [that] we basi- cally accept things if the surgeons don't want to accept them.}

Thus, turfing causes medical residents to feel used by others of greater authority, such as faculty or administrators, or by residents from other services who actually have their same level of training.

Mitigating Factors. According to the residents in the focus group, the relationship a resident forms with his or her patient can alleviate the frustration surrounding perceived inappropriate transfers. Other possible mitigating factors suggested were educational or financial incentives that could be built into the "balance" of transfers to offset the burdens, or a compensatory decrease in workload.

\section{Linguistic Analysis of Turfing}

Organization and Structure. Reviewing the linguistic characteristics of turfing excerpts, we found that they share four prominent organizational features. (For an example, see the following referenced lines in Table 1, where members of one team respond to learning that their resident missed an opportunity to block an admission and turf the patient to another service.) First, overlapped simulta- neous speech often blurs distinct turns at talk (lines 1217). Second, in a context of overlapping speakers, group hesitations and silences occur rarely. Even though individuals' speech may falter, group fluency prevails (lines 11-18). Third, the person of lowest medical rank who has the greatest responsibility for the patient's care-typically a third-year medical student or an intern-usually has the rights to the conversational floor. Despite multiple speakers, notice that "Gary" is the only one who pursues a line of discourse. The others provide background commentary. Finally, when comments made by a low-ranking primary speaker are directed to a person of greater authority, the speaker is supported by other participants of lower rank or lesser responsibility for the patient (all "Phillip" and "Jerome" lines).

Table 1. Sample Conversation

\begin{tabular}{|c|c|c|}
\hline Line & Speaker* & Statement ${ }^{\dagger}$ \\
\hline 1. & Gary: & $\begin{array}{l}\text {.. He should've gone to the ^Williams } \\
\text { service.. if he has a-- }\end{array}$ \\
\hline 2. & Phillip: & Oh Ted failed. \\
\hline 3. & & Ted failed. \\
\hline 4. & Gary: & He missed it. \\
\hline 5. & Phillip: & Ted failed. \\
\hline 6. & & He- he-- \\
\hline 7. & & Te-- \\
\hline 8. & Gary: & One slipped by him. \\
\hline 9. & Phillip: & Come\'ere. \\
\hline 10. & Ted: & Failed what? \\
\hline 11. & Phillip: & You owe us a [\be=er]. \\
\hline 12. & Gary: & [Schroeder ((patient))]-- \\
\hline 13. & & [[Schroeder has a]]-- \\
\hline 14. & Phillip: & [[You lose a \be=er]]. \\
\hline 15. & Gary: & [[[Schroeder has a]]]- \\
\hline 16. & Phillip: & {$[[[$ Lose a $\backslash \mathrm{be}=\mathrm{er}]]]$} \\
\hline 17. & Gary: & a- a in- \\
\hline 18. & & a . general medicine doc. \\
\hline 19. & & $\begin{array}{l}\text { [Sh- shouldn't] he have gone to the } \\
\text { Williams service? }\end{array}$ \\
\hline 20. & Phillip: & [Y- you lose]. \\
\hline 21. & & [[Lose a beer]]. \\
\hline $\begin{array}{l}22 . \\
23 .\end{array}$ & Gary: & $\begin{array}{l}\text { [[Pierre Sheppard's]] uh, } \\
\text { one of the interns. }\end{array}$ \\
\hline 24. & Jerome: & Yeah. \\
\hline 25. & & ((laughing)) Pierre's one of the interns. \\
\hline 26. & Phillip: & Lose a beer man. \\
\hline 27. & Ted: & ((groaning)) $\mathrm{O}=\mathrm{h}$ \\
\hline 28. & Phillip: & Minus one. \\
\hline 29. & & ((buzzer sound)) Nnnn. \\
\hline 30. & Gary: & $\begin{array}{l}\text { They sli- sli- they slipped one through } \\
\text { on us man. }\end{array}$ \\
\hline
\end{tabular}

*Rank of speakers: (1) Gary, intern, the primary caregiver of patient Schroeder; (2) Phillip, another intern, not from internal medicine; (3) Ted, resident; (4) Jerome, third-year medical student.

'Symbols: . pause, very short; .. pause, short; ^ accent on the following syllable; -, -- truncated word or phrase; $\backslash$ falling pitch of terminal syllable; = lengthening; [] speech overlap ([] overlaps with [], [[]] overlaps with [[]], etc); (0) researcher's comment. 
Lacking power within the culture of medicine, medical trainees on our tapes use the rhetorical strategies described above to assert themselves. Moreover, much of their vocabulary derives from sports and games, expressed in adversarial, rather than participatory terms. ${ }^{11}$ In the example in Table 1, "Phillip" chants a sort of mock chorus to voice collective dissatisfaction (lines 11,14,16,20,21,26,28,29) using the language of a "game" of admitting or rejecting patients.

Emotion. Conversation analysis shows how phonologic features of speech communicate nuances of mood, emotion, and intent. ${ }^{12}$ In the turfing excerpts, speakers animate their language with features such as volume emphasis, high vocal pitch, pressured delivery, sarcastic tone, and laughter. By contrast, most medical language (e.g., case presentations, lectures, consultations) uses economical, technical terms in the passive voice, nearly devoid of emotion. ${ }^{3}$ For example, the speakers in one excerpt (Table 2) convey frustration, anger, and ridicule using sarcasm and laughter. "Donna" is the intern on a team that has just received a patient from an established community subspecialist. As has happened before, that physician sent the patient without any prior telephone call, medical records, or documentation of the current problem. "Jack," the subspecialty fellow, has dealt with this physician before. Their conversation occurs in the presence of the rest of the team, but without the attending physician. In this context, the laughter and sarcasm reflect the trainees' emotional responses to the transfer process.

Residents readily admit their disregard for the physicians whom they perceive as sending turfs, "unhappy with the situation" as it exists in their professional training.

\begin{abstract}
And I think that's probably bad for patient care too because ... we have to relearn everything and . . we may miss out on little things just because, I mean, we're not that motivated cuz we already have these, you know, negative feelings.
\end{abstract}

And so they're [surgeons] asking us to do their, their grunt work, and that is frustrating. That is frustrating.

The focus group facilitator observes a big smile on the face of one resident when the group first starts talking about turfing. Later calling this to the resident's atten-

\section{Table 2. Sample Conversation}

\begin{tabular}{|c|c|c|}
\hline Line & Speaker & Statement \\
\hline 1. & Donna: & $\begin{array}{l}\text { You may mention that to him next time, } \\
\text { y'know, jus' wri- write us a two }\end{array}$ \\
\hline 2. & & or three-line transfer note would be helpful. \\
\hline 3. & & (Jack laughs) \\
\hline 4. & Donna: & Like a chief complaint? \\
\hline 5. & Jack: & $\begin{array}{l}\text { He thinks we steal his patients. He's } \\
\text { accused us of that before. }\end{array}$ \\
\hline 6. & Donna: & He can have'em. \\
\hline 7. & & (Jack and team laugh.) \\
\hline
\end{tabular}

tion, the facilitator notes that at times others smile about turfing, too. The resident thinks a bit, then replies, "Well, you smile, I guess, because it's a game, because it's so sad, really." Others concur, "Yeah, it's very sad." The resident continues, “. . . if you didn't laugh, make it a game, you couldn't do it.”

Indeed, the residents in our focus group gratefully describe a sense of catharsis after spending $11 / 2$ hours telling stories, analyzing, and discussing the issue of turfing. The facilitator discovers that the participants "are suffering. You can hear it in the pleading quality to their voices. . . [They] talked about hits and getting killed and pain. I said. . . it sounds like you're in pain! A resounding, 'We are!'”

\section{DISCUSSION}

On the basis of turfing excerpts from an earlier study, we initially devised a conceptual framework that reflected a conflict between two values: responsibility to the patient and the perceived duty of clinical service. ${ }^{1}$ The tapes suggest that residents perceive patient transfers as a matter of balance: if particular conditions of patient care are not met, or certain cultural norms are violated, then the balance would be shifted from an appropriate transfer to an inappropriate turf. We base our conceptual framework on this metaphor of balance.

Residents decide whether a particular patient is an appropriate transfer or a turf by considering the characteristics of continuity, effectiveness, and power. At one extreme, a patient is labeled an appropriate transfer if sent to the teaching hospital's medical service because that is where the primary care provider practices, if the patient needs a treatment only available at that hospital, or if the transferring physician does not rely on the power imbalance inherent in the organization to accomplish the transfer. Conversely, if the patient is transferred away from his or her primary care provider, has no treatment plan, or is transferred to someone who is powerless to refuse the patient, that patient is considered a turf. Between these extremes, the degree of perceived appropriateness is variable, depending on the workload of the individual resident receiving the patient and the relative proportion of the characteristics of continuity, effectiveness, and power. In all these situations the patient moves passively from one end of this balance beam to the other, subject to the perceptions and actions of the transferring and receiving doctors.

When the label of turf is applied, there is a tacit accusation that the transferring physician has abrogated his or her duty to the patient. Transferring physicians' professional roles represent the fulcrum around which residents describe their conflict between responsibility to patients and duty to serve. ${ }^{1}$ Residents respond with anger, frustration, and hostility. They feel "used" rather than "utilized," and chafe at the burdens of the service they are called on to provide. When a patient is appropriately 
transferred, there are no such negative feelings, and the residents talk about their medical service as an honor and a privilege.

Yet one might wonder why the patient is called a turf and not the transferring physician. Why don't we hear residents saying "That turf in ortho just sent me another one"? We wondered why the residents don't label the actor with the action. One explanation derives from the language with which subordinates express resistance to their superiors. Couched in pejorative terms about patients, medical residents complain to each other about empowered physicians using a "hidden transcript." 13 Residents feel dominated by the turfer and repress uttering their emotional critiques directly to the turfer. Outside the presence of the transferring physician, they can voice their anger at his or her behavior in a nonthreatening, face-saving way. Behind the turfer's back, the residents redirect their dissatisfactions to other, less powerful persons, such as patients. Thus, when residents are in a subordinate position and powerless to refuse a transfer, they express their frustration and criticism in a way that allows them to maintain their own sense of power and control.

Returning to our observations of the structure and organization of turfing discourse, we note that as with conversations in other settings, ${ }^{8}$ the turfing excerpts display a social organization constructed and understood by the participants. Multiple overlapped voices sound harmonious, suggesting accord and conviction, not conflict. The most junior member of the team (who has the greatest responsibility for the patient's care, yet who also bears the greatest burden of the turf) is empowered conversationally with a voice to hold the floor. Conversational support from other speakers of lower rank or lesser responsibility may enact solidarity, while simultaneously acknowledging the power structure of the medical hierarchy.

We have little data from our residents about how they cope with the emotional stress of receiving a turf. From linguistic analysis, we see that turfing conversations can provide an outlet for anger and frustration by virtue of their emotionality. Although useful, such venting exemplifies an indirect style of handling interprofessional conflicts. The emotionality of turfing conversations reveals the extent of these residents' personal involvement in situations of perceived inappropriate patient transfers. Because such emotionality is uncharacteristic of medical discourse, we feared that these residents' negative feelings or dysfunctional coping mechanisms might adversely affect their relationships with and care of their patients. Much of our data reassured us that somehow the residents are able to leave their antagonism toward the transferring physicians at the door to the patient's room. Nevertheless, their suggested incentives (educational, financial, and compensatory decrease in workload) aroused our concern that the organizational structure of medical training might be inhibiting the development of moral tenets of our profession.

Thus, we suggest that another potential means to vent frustration might be for faculty to talk with residents about the issues of turfing when they arise in clinical practice. Attending physicians could be alert for the use of the language of turfing, and use this as an opportunity to discuss power, continuity, and effectiveness with residents and to model more direct and collegial ways of handling professional conflicts. If our trainees are "pleading" (in the words of our focus group facilitator) it is up to faculty to heed their call.

We readily admit the bias inherent in this type of research; our interpretations are flavored by our experiences and our interactions with specific colleagues and students. The taped conversations, in fact, were uniquely helpful in expanding our understanding of this complex issue. We studied a small group (one residency program) located at only one institution. Admittedly, different conclusions may be reached at other sites or types of residency programs. Indeed, the environment described in this article depends heavily on its context as a tertiary care academic center. Nevertheless, these findings resonate with our own and others' personal residency experiences at other tertiary care teaching institutions so that our findings may be relevant to these sorts of training programs. We might expect that the issues of turfing are less relevant or have alternative meanings in other environments (e.g., community hospitals, managed care settings) where different elements contribute to the conceptual framework of balance in patient care. We look forward to further research in these areas.

We also studied only internal medicine residents, which necessarily limits our hypotheses about broader conceptions of turfing among residents and practicing physicians in other specialties. The views of residents from other specialties, particularly from surgery, would be a fruitful area for future investigation. This report provides a "snapshot" of one group of residents' attitudes, and it would be interesting to explore how these residents' attitudes change with time, with additional training, and as they move from one organizational setting to another. In addition, the data from the focus group may be biased in its representation of residents' justifications of their own behavior, rather than an honest explanation or description.

Linguist Deborah Keller-Cohen calls language "a signpost for ideology" (personal communication). In this analysis of the language of internal medicine residents, we begin to uncover a part of their ideology: Residents can feel angry and frustrated about receiving patients seemingly rejected by other doctors, while feeling powerless to prevent the transfer of patients for whom they can offer neither effective treatment nor continuous relationship.

The language of turfing may indeed be a means for residents to cope with some of the frustrations and anxieties created in an environment in which they are often overworked and tired, and over which they have little control. Faculty mentors can help residents bring these issues into the open and express them in ways that are constructive for learning patient care and effective interprofessional relationships. 
Yes, it's painful, it's a hit, but once you see the patient I think a lot of those feelings go away when you feel, oh wow, this is a real person, and you can empathize with 'em and help them out as much as possible. And you get something out of that.

The authors are indebted to the residents, students, and faculty of the Department of Internal Medicine at the University of Michigan for their participation and assistance with this research. The comments of Renée Anspach, Susan Goold, Rodney Hayward, Joel Howell, Deborah Keller-Cohen, Lawrence McMahon, and James Woolliscroft were particularly useful in developing the concepts included in this paper. The authors thank Clare Weipert for her expert technical assistance in the transcription of audiotapes and manuscript preparation.

This work was supported by the Lyle C. Roll Fund for Humane Medicine and the Robert Wood Johnson Clinical Scholars Program.

\section{REFERENCES}

1. Stern DT. Hanging Out: Teaching Values in Medical Education. Stanford, Calif: Stanford University; 1996. Dissertation.
2. Oxford English Dictionary. 2nd ed. New York, NY: Oxford University Press; 1996. Turf; electronic search.

3. Anspach RA. Notes on the sociology of medical discourse. J Health Soc Behav. 1988;29:357-75.

4. Stern DT. Values on call: a method for assessing the teaching of professionalism. Acad Med. 1996;71(10 suppl 1):S37-9.

5. Patton MQ. Qualitative Evaluation and Research Methods. 2nd ed. Newbury Park, Calif: Sage; 1990.

6. DuBois JW, Schuetze-Coburn S, Paolino D, Cumming S. Santa Barbara Linguistics, Vol. 4, Discourse Transcription. Santa Barbara, Calif: Department of Linguistics, University of California; 1992.

7. Ochs E, Capps L. Narrating the Self. Annual Review of Anthropology. 1996;26:18-43.

8. West C, Zimmerman DH. Conversation analysis. In: Scherer KR, Ekman P, eds. Handbook of Methods of Nonverbal Behavior Research. New York, NY: Cambridge University Press; 1982:506-41.

9. Miles MB, Huberman AM. Qualitative Data Analysis. 2nd ed. Thousand Oaks, Calif: Sage; 1994.

10. Anspach R. Deciding Who Lives: Fateful Choices in the IntensiveCare Nursery. Berkeley, Calif: University of California Press; 1993.

11. Hardison JE. Benefit of the doubt. Am J Med. 1985;79:401-2.

12. Cassell EJ. Talking with Patients, Vol. 1. Cambridge, Mass: The MIT Press; 1985

13. Gal S. Language and the "arts of resistance." Cultural Anthropology. 1995;10(3):407-24.

\section{JOURNAL OF GENERAL INTERNAL MEDICINE SUBSCRIBERS Do we have your new address?}

Send us your new address three months before it becomes effective, so we will have time to get it into our computer system and ensure that your copies of JGIM continue to arrive uninterrupted. Send your old mailing label, your new address with zip code, the effective date of your new address, and your current telephone number.

$$
\begin{gathered}
\text { Nonmember subscribers notify: } \\
\text { Tina Lynch } \\
\text { Blackwell Science, Inc. } \\
\text { Commerce Place, } 350 \text { Main St. } \\
\text { Malden, MA } 02148
\end{gathered}
$$

\section{SGIM members notify:}

Janice L. Clements

Society of General Internal Medicine 2501 M Street, NW, Suite 575

Washington, DC 20037 